\title{
Perancangan Aplikasi Anatomi dan Fisiologi pada Sistem Kardiovaskular sebagai Pendukung Pembelajaran Mahasiswa Kedokteran Umum
}

\author{
Ade Nobi Miranto dan Kartika Kusuma Wardani \\ Departemen Desain Komunikasi Visual, Fakultas Arsitektur Desain dan Perencanaan, \\ Institut Teknologi Sepuluh Nopember (ITS) \\ e-mail:kartikawardani.its@gmail.com
}

\begin{abstract}
Abstrak-Anatomi dan fisiologi adalah ilmu dasar yang harus dikuasai oleh mahasiswa kedokteran. Banyaknya materi yang harus dipelajari membuat mahasiswa kedokteran mengalami kesulitan dalam mengingatnya. Untuk mengatasi hal tersebut, mahasiswa kedokteran banyak yang menggunakan video dan aplikasi. Sehingga, penelitian ini diharapkan dapat membantu mahasiswa dalam menghafalkan materi anatomi dan fisiologi dengan tetap memberi ruang untuk mahasiswa kedokteran mempelajari dengan cara yang kreatifnya masingmasing. Metode yang dilakukan dalam perancangan ini, yaitu dengan melakukan studi eksploratif kepada mahasiswa kedokteran tentang cara belajar anatomi dan fisiologi, dengan menyebarkan kuisioner, melakukan wawancara, dan mempelajari personal inventory mereka, berupa catatan yang telah mereka buat. Selanjutnya, konten anatomi dan fisiologi dipelajari dengan melakukan studi literatur berupa buku anatomi dan fisiologi. Materi anatomi dan fisiologi dalam perancangan ini dibatasi hanya pada sistem kardiovaskular. Perancangan ini menghasilkan luaran berupa aplikasi anatomi dan fisiologi yang memiliki konsep "Personal Journal for Future Doctor". Aplikasi anatomi dan fisiologi ini memiliki fitur catatan, animasi, tombol interaktif, dan dilengkapi dengan jurnal visual sebagai buku aktivitas dan catatan. Oleh karena terancangnya aplikasi anatomi dan fisiologi ini, diharapkan mahasiswa kedokteran dapat berhasil terbantu dalam belajar anatomi dan fisiologi.
\end{abstract}

Kata Kunci-Aplikasi, Anatomi dan Fisiologi, Desain Antarmuka, Kardiovaskular, Mahasiswa Kedokteran.

\section{PENDAHULUAN}

CAAT menempuh pendidikan kedokteran, seorang mahasiswa kedokteran harus menguasai ilmu biomedik, ilmu humaniora kedokteran, ilmu kedokteran klinik, dan ilmu kesehatan masyarakat dengan memerhatikan prinsip metode ilmiah dan prinsip kurikulum spiral [1]. Dalam ilmu biomedik yang harus dikuasai mahasiswa kedokteran, terdapat ilmu anatomi dan fisiologi yang menjadi landasan berpikir ilmiah dalam menangani pasiennya. Menurut Standar Kompetensi Dokter Indonesia, seorang dokter harus menguasai materi koordinasi regulasi antar organ atau sistem, di antaranya: integumen, skeletal, kardiovaskular, respirasi, gastrointenstinal, reproduksi, tumbuh-kembang, endokrin, nefrogenitalia, darah dan sistem imun, serta saraf pusatperifer dan indra [1].

Materi yang harus dikuasai oleh mahasiswa kedokteran dalam anatomi dan fisiologi sangat banyak dan rumit. Secara keseluruhan, materi yang dipelajari dalam anatomi dan fisiologi adalah semua struktur yang membentuk tubuh manusia dan segala proses fungsi yang terjadi di dalamnya. Mahasiswa kedokteran harus mempelajari dari struktur anatomi yang makro hingga struktur anatomi yang sangat rumit dalam anatomi mikro. Dalam sistem perkuliahan saat ini, materi tersebut dibagi dalam beberapa blok dan mahasiswa kedokteran harus menguasainya dalam kurun waktu yang singkat. Oleh karena itu, dalam mempelajari materi anatomi dan fisiologi tersebut, mahasiswa kedokteran memiliki beberapa metode, yaitu dengan praktikum, problem-based learning, kuliah pakar, dan belajar mandiri. Namun, masih saja terdapat kesulitan yang ditemui oleh mahasiswa kedokteran dalam mempelajarinya.

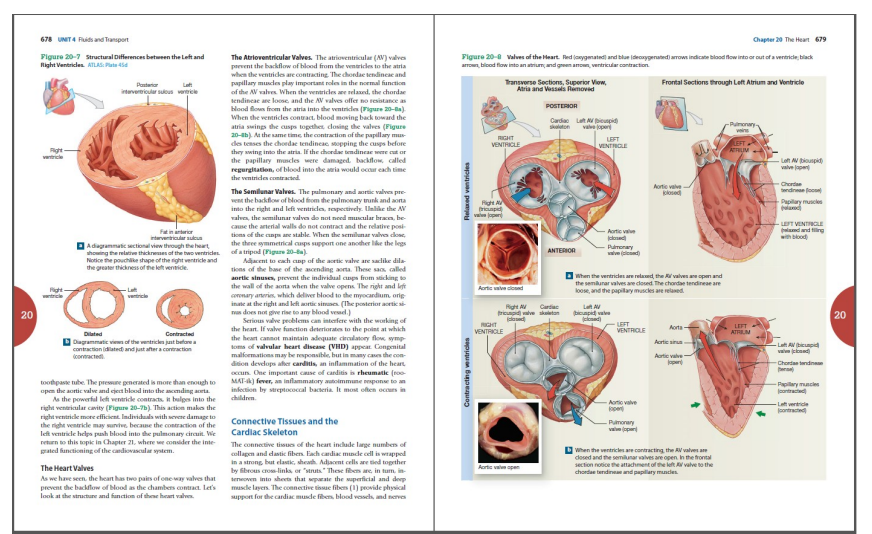

Gambar 1. Isi buku anatomi dan fisiologi dengan gambar penjelasan dari buku Fundamentals of Anatomy [2].

Beragam media pembelajaran dibutuhkan mahasiswa karena banyak mahasiswa kedokteran yang masih merasa kesulitan dalam memahami konten dari buku-buku kedokteran saat ini. Sehingga, buku teks tersebut hanya menjadi sumber materi bagi mahasiswa kedokteran yang hanya dibuka sesekali ketika mereka hendak mencari informasi tertentu. Kesulitan yang dialami mahasiswa kedokteran dalam memahami konten buku kedokteran dikarenakan oleh gaya penulisannya yang terlalu rumit dan grafisnya yang belum mampu mengkomunikasikan materi dengan mudah. Buku kedokteran yang ditulis oleh ilmuwan kedokteran memuat banyak materi dan memiliki penulisan yang sangat ilmiah dan mendetail. Tak jarang juga ditemui buku kedokteran yang memuat banyak deskripsi daripada grafis yang mendukung konten buku tersebut, sehingga hal tersebut membuat pembaca merasa berat dalam mempelajarinya. Selain itu, grafis yang ada pada buku kedokteran belum sepenuhnya dapat mengkomunikasikan konten yang ingin disampaikan. Grafis pendukung sangat dibutuhkan untuk memperjelas dan memvisualkan konten yang telah dituliskan pada buku kedokteran.

Di sisi lain, media pembelajaran dalam bentuk media audiovisual sudah sangat banyak beredar dan dapat diakses dengan mudah. Mahasiswa kedokteran dapat dengan 
mudah menonton video animasi atau penjelasan dari ahli mengenai materi anatomi dan fisiologi melalui Youtube. Sedangkan untuk aplikasi pendukung pembelajaran materi anatomi dan fisiologi, mahasiswa kedokteran bisa mendapatkannya di Play Store dan Apps Store. Macam aplikasi yang telah beredar di Play Store dan Appstore juga cukup beragam. Ada yang menawarkan bentuk tiga dimensi dari struktur anatomi, kuis, permainan, animasi, dan lain lain. Dari survey yang telah dilakukan, terdapat 5.360 kanal dan 785.000 video di Youtube yang membahas tentang anatomi dan fisiologi. Sedangkan untuk aplikasi, terdapat 242 aplikasi anatomi dan fisiologi yang telah dikembangkan dan dipublikasikan di Play Store. Tetapi, dari banyaknya video dan aplikasi, masih sedikit video atau aplikasi berbahasa Indonesia yang dapat memenuhi kebutuhan belajar mahasiswa kedokteran secara praktis.

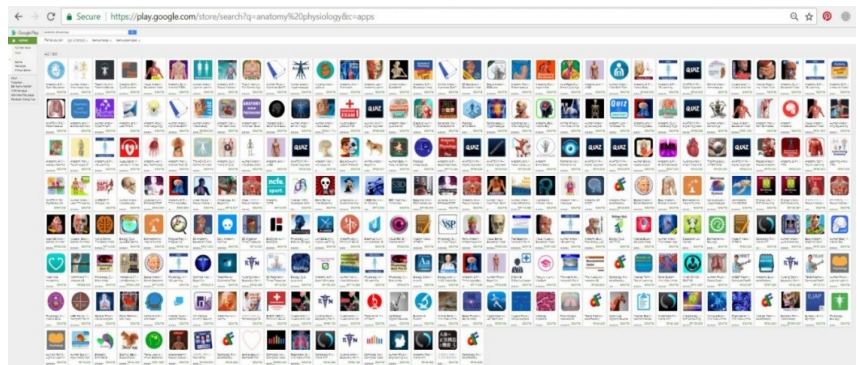

Gambar 2. Halaman penelusuran play store tentang aplikasi anatomi dan fisiologi.

Fenomena-fenomena yang telah dijelaskan kemudian dijabarkan menjadi rumusan masalah. Rumusan masalah yang akan diselesaikan melalui perancangan ini adalah bagaimana merancang aplikasi yang dapat membantu mahasiswa kedokteran dalam mempelajari ilmu anatomi dan fisiologi pada sistem kardiovaskular. Perancangan ini akan membahas anatomi dan fisiologi pada sistem kardiovaskular yang mencakup anatomi struktur pembuluh darah, anatomi struktur jantung, komponen dalam darah, proses pembentukan sel darah, proses koordinasi pembuluh darah dan jantung, mekanik jantung, tekanan darah dan resistensi, dan sirkuit pembuluh darah. Fokus media yang digunakan adalah aplikasi ponsel berbasis android. Studi dilakukan dengan mengambil sampel dari mahasiswa kedokteran umum di beberapa Universitas di Indonesia.

Perancangan ini dilakukan dengan tujuan membantu pembelajaran mahasiswa kedokteran di tingkat sarjana. Mahasiswa kedokteran diharapkan dapat lebih mudah dalam mengingat materi anatomi dan fisiologi dengan menggunakan aplikasi.

\section{II.METODOLOGI DAN ANALISIS PENELITIAN}

Berikut ini adalah alur penelitian dan proses desain dalam perancangan aplikasi anatomi dan fisiologi.

\section{A. Metode Penelitian}

\section{1) Kuisioner}

Kuisioner disebarkan melalui situs Google Form kepada 127 responden dengan latar belakang sebagai mahasiwa kedokteran dari 12 universitas di Indonesia. Dari 127 responden yang merupakan mahasiswa kedokteran, sebanyak 76 responden (59.8\%) mengaku kesulitan dalam mempelajari anatomi dan fisiologi menggunakan buku teks. Sedangkan, sebanyak 40,2\% dari 127 responden tidak mengalami kesulitan dalam mempelajari materi anatomi dan fisiologi dengan buku teks.

2) Depth Interview

Wawancara dilakukan secara online melalui media sosial Line dengan 5 mahasiswa kedokteran, yaitu Bella Dicky Wibowo dari Universitas Airlangga, Yudha Kusuma Dwiatmadja dari Universitas Gajah Mada, Linati Shabrina dari Universitas Brawijaya, Ashandi Triyoga Prawira dan Muhammad Faizal Akbar dari Universitas Jember. Dari wawancara tersebut didapatkan cara-cara belajar anatomi dan fisiologi yang berbeda beda dan pendapat mengenai penggunaan media pendukung pembelajaran dengan lebih dalam.

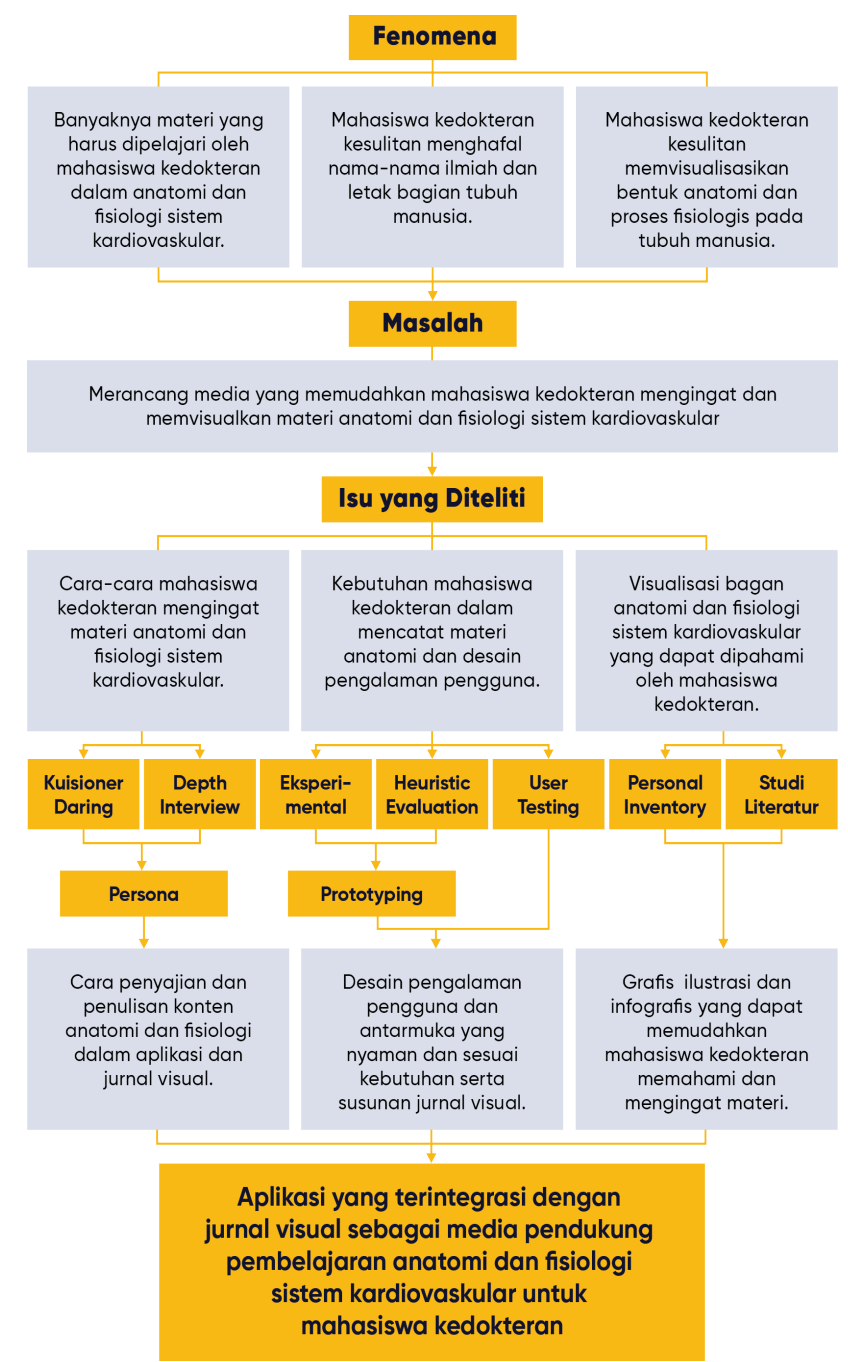

Gambar 3. Kerangka penelitian perancangan aplikasi anatomi dan fisiologi

\section{3) Personal Inventory}

Metode personal inventory dilakukan dengan mengambil sampel catatan yang ditulis oleh mahasiswa kedokteran. Dari penelitian ini, berhasil didapatkan catatan dari salah satu mahasiswa kedokteran bernama Muhammad Faizal Akbar dari Universitas Jember yang dapat mendukung data dalam merancang ilustrasi dan penyajian materi.

4) Studi Literatur

Studi literatur dilakukan dengan cara mempelajari kembali materi anatomi dan fisiologi sistem kardiovaskular dari buku atlas anatomi dan buku teks anatomi dan fisiologi. Dengan melakukan studi literatur, data yang didapatkan berupa daftar konten yang harus dimasukkan dan inti dari materi anatomi dan fisiologi sistem kardiovaskular yang perlu diingat oleh mahasiswa kedokteran. Dalam studi literatur, penulis membaca isi 
keseluruhan buku teks dan merangkumnya kembali menjadi pokok-pokok informasi yang utama. Ilustrasi anatomi yang terdapat pada buku juga diolah kembali menjadi lebih sederhana namun tetap komunikatif agar dapat diingat lebih mudah.

\section{5) Persona}

Setelah mendapatkan data dan menentukan target audiens, langkah selanjutnya adalah mengelompokkan pengguna dan membuat persona sebagai acuan. Desain yang dibuat disesuakan dengan kebutuhan setiap persona.

\section{6) Heuristic Evaluation}

Heuristic evaluation adalah evaluasi awal yang dilakukan untuk meminimalisir terlalu banyaknya kesalahan teknis pada kinerja aplikasi dan biaya yang telalu banyak yang dapat dihabiskan untuk melakukan pengujian berulang-ulang. Evaluasi ini mencakup evaluasi terhadap fungsi navigasi dan perbaikan bug. Evaluasi ini dilakukan kepada beberapa orang mahasiswa desain yang memahami desain antarmuka di luar target pengguna aplikasi.

\section{7) User Testing}

Purwarupa aplikasi diujikan kepada beberapa mahasiswa kedokteran di Fakultas Kedokteran Universitas Airlangga. Pengujian aplikasi bertujuan untuk mendapatkan respon berupa saran dan evaluasi untuk memperbaiki purwarupa. Respon yang diharapkan berupa masukan terhadap desain antarmuka, fitur, keterbacaan tulisan, dan konten materi pada aplikasi.

\section{B. Populasi}

Populasi berhubungan dengan data yang dihasilkan dari objek penelitian. Pada penelitian ini populasi yang dipilih berdasarkan studi kepada mahasiswa kedokteran. Spesifikasi populasi yang dipilih, yaitu:

1) Segmentasi geografis

Studi dilakukan pada subyek yang belajar di fakultas kedokteran universitas negeri di Indonesia

2) Segmentasi demografis

Studi dilakukan pada subyek laki-laki dan perempuan berusia 18-23 tahun dengan latar belakang mahasiswa kedokteran.

3) Segmentasi psikografis

Subyek penelitian ini adalah audiens yang menggunakan alternatif media pembelajaran lain selain buku teks, memiliki cara belajar yang kreatif, senang belajar berkelompok, dan mengalami kesulitan dalam mempelajari materi anatomi dan fisiologi.

\section{KONSEP DESAIN}

Konsep perancangan aplikasi ini dirancang berdasarkan analisis data yang telah dilakukan, yaitu analisis hasil wawancara, analisis kuisioner, analisis personal inventory, dan studi materi anatomi dan fisiologi sistem kardiovaskular. Dari analisis tersebut, big idea dapat ditentukan sebagai dasar utama dalam perancangan aplikasi sesuai kebutuhan target audiens. Big idea dari perancangan ini adalah "Personal Journal for Future Doctors". Keyword untuk konsep perancangan ini adalah modern, creative, personal. Konsep ini menggambarkan sebuah media pendukung pembelajaran yang dapat disesuaikan sendiri oleh mahasiswa kedokteran yang merupakan calon dokter untuk masa depan.

\section{A. Konsep Visual}

Dari kriteria keyword yang digunakan dan menyesuaikan dengan fenomena yang dialami oleh target audiens, perancangan ini menggunakan konsep visual dengan warna terang yang kontras dan ilustrasi sederhana yang komunikatif. Warna yang terang dipilih dengan alasan untuk menimbulkan ketajaman visual sehingga pengguna dapat lebih mudah mengingat informasi yang ada di dalamnya. Selain itu, keseharian mahasiswa kedokteran yang berkutat dengan kadaver, menimbulkan kebutuhan mahasiswa kedokteran akan visual yang dapat memberikan penyegaran dari visual kadaver yang menjemukan. Sehingga, perancangan ini memiliki konsep visual pop dan modern. Ilustrasi yang dibunakan merupakan ilustrasi yang sederhana dengan penggunaan outline. Hal tersebut dikarenakan informasi penting yang perlu untuk dihafalkan adalah topografi dari struktur anatomi. Outline, membantu untuk mempertegas batas dan perbedaan antar bagian pada suatu struktur anatomi. Dengan luaran berupa aplikasi, aspek visual terbagi menjadi dua bagian, yaitu aspek visual pada desain antarmuka aplikasi dan gaya ilustrasi anatomi. Desain antarmuka disesuaikan dengan gawai yang ideal untuk mahasiswa kedokteran dalam mempelajari materi secara praktis.

\section{B. Konsep Aplikasi}

"Lemi Notes" adalah kesimpulan dari what to say dan keyword yang menggambarkan mahasiswa kedokteran memiliki kebebasan untuk menggunakan cara kreatif pada aplikasi ini untuk mempelajari anatomi dan fisiologi sistem kardiovaskular. "Lemi Notes" berasal dari kata let me notes yang berarti biarlah aku mencatat. Nama dari aplikasi ini menggunakan bahasa Inggris untuk memenuhi kriteria keyword, yaitu modern.

Aplikasi yang dirancang membahas tentang anatomi dan fisiologi pada sistem kardiovaskular, yaitu ilmu yang mempelajari tentang struktur dan fungsi pada organ jantung, pembuluh darah, dan aliran darah pada tubuh manusia. Untuk memudahkan pembelajaran, materi sistem kardiovaskular dibagi menjadi tiga bagian, yaitu jantung, pembuluh darah dan darah. Pada bagian materi jantung, aplikasi ini membahas tentang struktur topografi hingga bagian dalamnya, mekanisme kerjanya, serta peran jantung sebagai alat pompa darah. Pada bagian materi pembuluh darah, aplikasi ini membahas tentang jenis jenis pembuluh darah hingga persebrannya di seluruh tubuh. Sedangkan pada bagian materi darah, materi yang dibahas adalah karakteristik darah, komposisi darah, fungsi darah, hingga jenis-jenis sel darah.

\section{Arsitektur Informasi}

Untuk merancang alur pengalaman pengguna pada apikasi, arsitektur informasi duperlukan sebagai acuan dalam membuat halaman dan navigasi. 


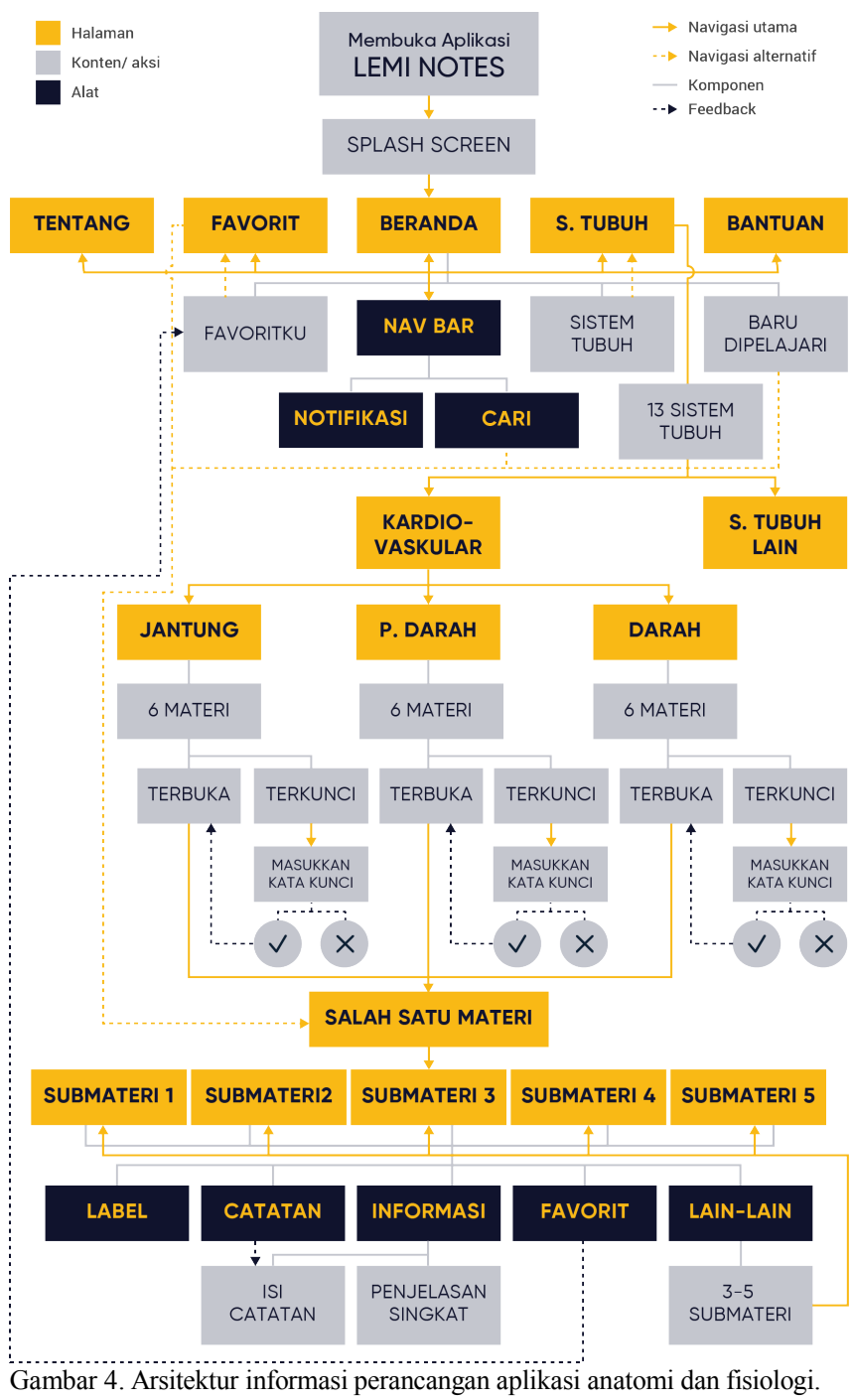

\section{Wire Frame}

Konsep aplikasi digambarkan melalui visual sederhana yang mewakili keseluruhan aplikasi, yaitu wireframe. Wireframe akan menjadi acuan dalam penataan elemen desain antarmuka aplikasi. Pembuatan wireframe merupakan pengembangan arsitektur informasi menjadi beberapa tampilan halaman seperti berikut.
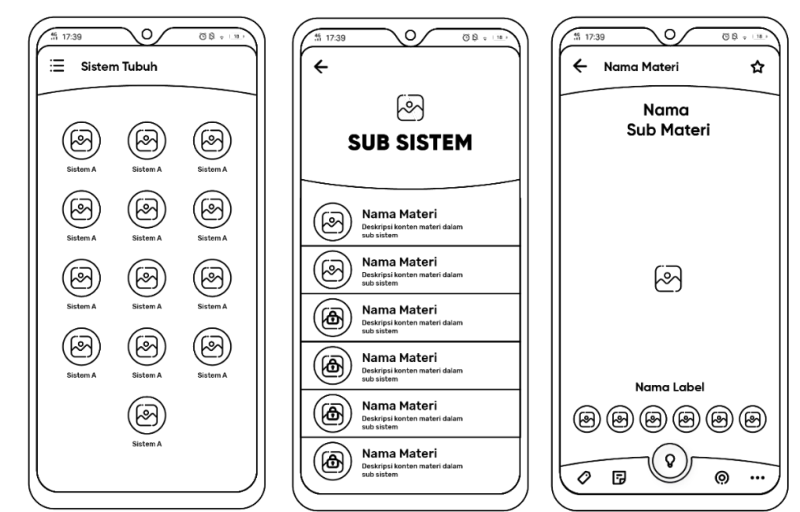

Gambar 5. Wire frame aplikasi anatomi dan fisiologi.

\section{E. Desain Antarmuka}

\section{1) Warna}

Warna aplikasi ditentukan dengan melihat warna-warna aplikasi kedokteran yang sudah ada dan mempertimbangkan konsep visual yang telah ditetapkan. Dari perbandingan warna pada aplikasi tersebut, aplikasi anatomi dan fisiologi, seperti Elsevier Sobotta lebih memiliki warna cerah dan ringan dibandingan dengan aplikasi lainnya.

Penggunaan warna yang cerah dan ringan lebih cocok dengan konsep aplikasi dalam perancangan ini. Sehingga, aplikasi ini menggunakan warna kuning amber yang cerah sebagai warna primernya. Untuk warna sekunder, aplikasi ini menggunakan warna yang komplementer dengan kuning amber yaitu warna biru tua. Kesan yang diharapkan dengan pengggunaan warna kuning amber, yaitu kreatif dan cerah. Sedangkan warna biru diharapkan dapat memberi kesan ketekunan dalam belajar dan edukasi.

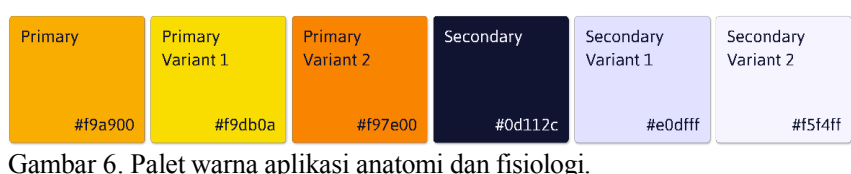

\section{2) Tipografi}

Tipografi yang digunakan dalam aplikasi adalah jenis font sans serif. Font yang digunakan adalah Gilroy dan Rubik. Gilroy dan Rubik digunakan karena keterbacaan yang baik dan kesan yang modern. Gilroy memiliki anatomi huruf yang terlihat geometris dan bentuk lingkaran sempurna pada huruf "o" dan "a". Sedangkan, Rubik memiliki anatomi huruf yang lebih condensed dibandingkan Gilroy. Rubik lebih cocok digunakan pada konten paragraf karena memiliki huruf "a" kecil yang memiliki ascender melengkung. Dengan begitu, huruf "a: kecil lebih mudah dibedakan dengan huruf "o" kecil.

\section{3) Ikon}

Ikon produk dari aplikasi "Lemi Notes" menggunakan logo primer dari aplikasi. Bentuk ikon yang bundar lebih fleksibel untuk digunakan di beberapa macam versi Android dan terlihat lebih sederhana.

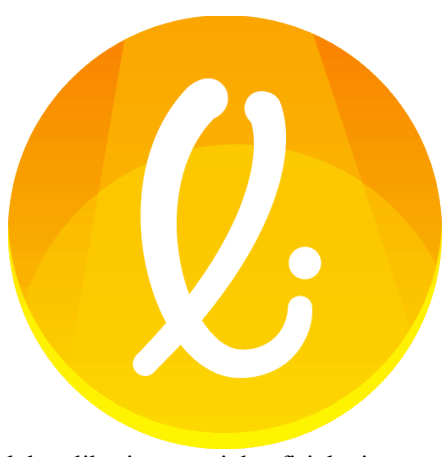

Gambar 7. Ikon produk aplikasi anatomi dan fisiologi.

Ikon yang digunakan pada desain antarmuka aplikasi menggunakan dasar bentukan geometris. Ikon didesain sesederhana mungkin dan komunikatif agar pengguna dapat menjalankan aplikasi dengan mudah. Ikon dibuat berdasarkan kajian literatur dari website material design.io yang telah dibuat oleh Google sebagai standar pembuatan ikon. 


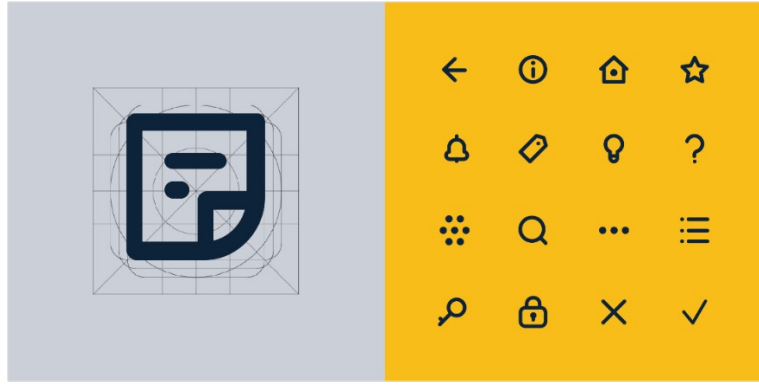

Gambar 8. Ikon sistem pada aplikasi anatomi dan fisiologi.

\section{IMPLEMENTASI DESAIN}

\section{A. Implementasi Tipografi}

Desain akhir aplikasi menggunakan dua jenis font, yaitu Gilroy dan Rubik. Gilroy akan digunakan sebagian besar sebagai font pada judul. Sedangkan Rubik sebagian besar digunakan untuk keterangan dan konten materi.

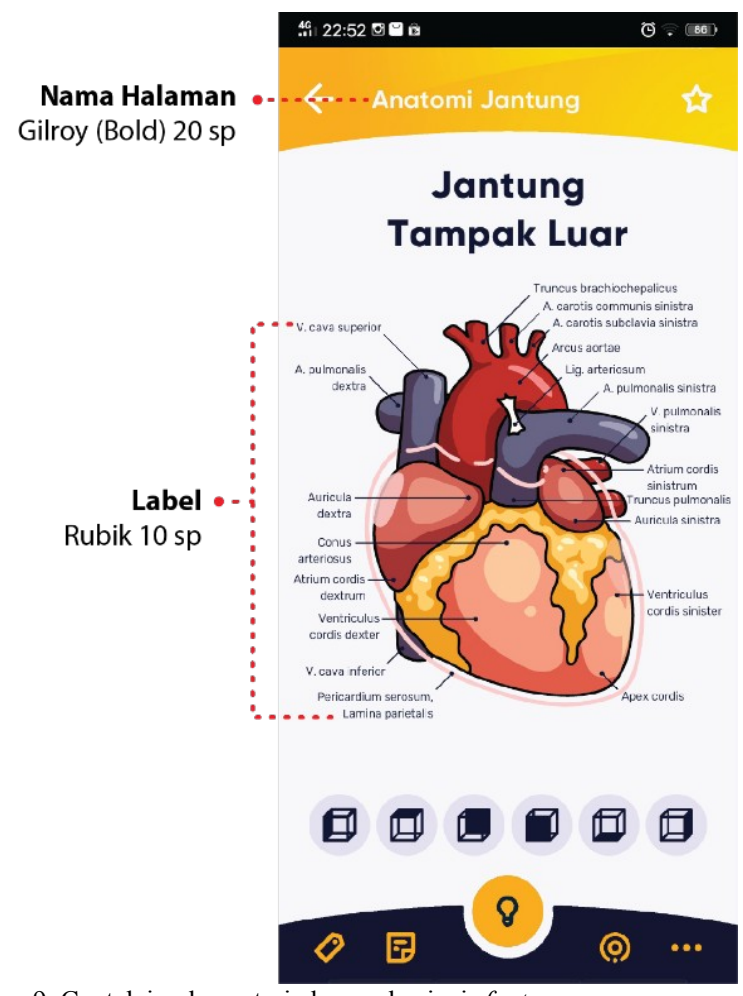

Gambar 9. Contoh implementasi ukuran dan jenis font.

\section{B. Implementasi Ukuran Jarak dan Margin}

Pada halaman beranda terdapat tiga segmen utama, yaitu pilihan sistem tubuh, materi baru dipelajari, dan materi favorit. Tinggi ukuran segmen pilihan sistem tubuh pada beranda adalah $118 \mathrm{dp}$ dan terdiri dari tombol-tombol ikon lingkaran yang dapat digeser. Segmen materi yang baru dipelajari dan materi favorit terdiri dari kartu-kartu berilustrasi yang berjajar horizontal sebanyak tiga kolom. Setiap kartunya memiliki dimensi 192dp x 104 dp.

Halaman materi memiliki beberapa fitur dan bilah yang dapat dimunculkan. Fitur dan bilah tersebut dimunculkan dengan menyentuh ikon-ikon yang berukuruan $24 \mathrm{dp}$. Fitur dan bilah yang muncul tersebut antara lain, yaitu bilah pilihan submateri, bilah informasi, dan fitur catatan. Bilah pilihan submenu memiliki hingga lima pilihan submenu. Tiap pilihannya memiliki dimensi sentuh sebesar $56 \mathrm{dp} \mathrm{x}$ 272 dp. Sedangkan, bilah informasi dan fitur pencatatan memiliki bidang yang memenuhi ukuran layar. Ukuran ruang tulisan minimal pada bilah informasi sebesar $356 \mathrm{dp}$ x 320dp, sedangkan pada fitur pencatatan sebesar $600 \mathrm{dp} \mathrm{x}$ 320 dp. Terdapat juga tombol batal dan oke di bagian atas fitur pencatatan yang memiliki ruang sentuh selebar 144 dp.

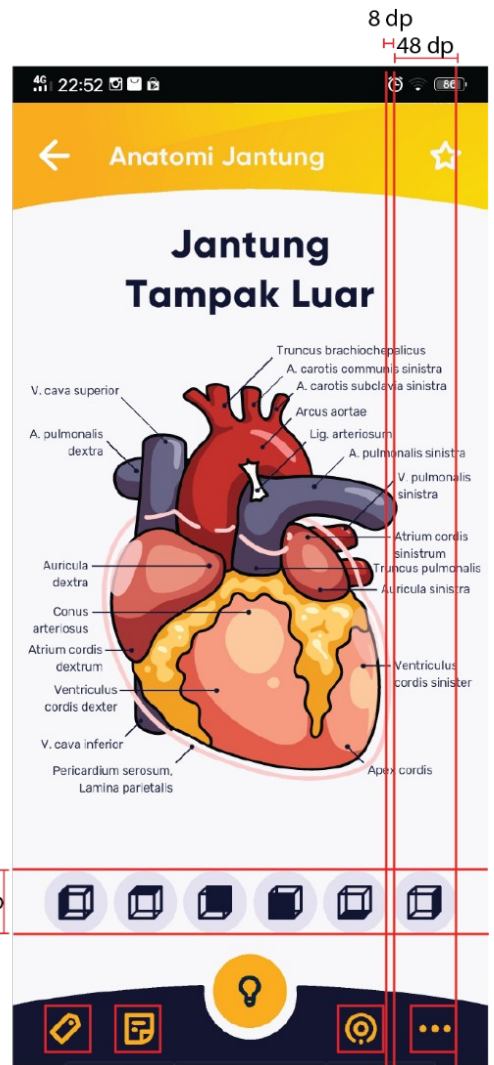

Gambar 10. Implementasi ukuran jarak dan margin pada halaman materi.

\section{Hasil Desain Akhir}

Hasil akhir dari perancangan ini adalah berupa aplikasi mobile dengan platform android. Hasil desain akhir aplikasi tersebut dapat dilihat dalam bentuk mock up sebagai berikut:
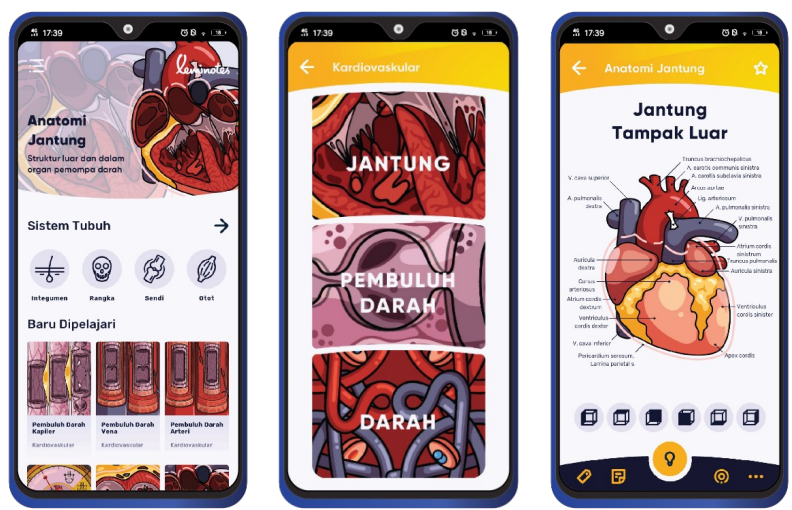

Gambar 11. Tampilan hasil akhir aplikasi dalam mock up ponsel android.

\section{V.KESIMPULAN DAN SARAN}

\section{A. Kesimpulan}

Mahasiswa kedokteran memiliki cara mereka sendiri untuk menghafalkan materi anatomi dan fisiologi dengan mudah. Salah satu caranya adalah menggunakan aplikasi. Aplikasi hasil luaran perancangan ini, mahasiswa kedokteran diharapkan dapat terbantu dalam mengingat materi anatomi dan fisiologi pada sistem kardiovaskular, 
tetapi masih memenuhi kebutuhan mahasiswa untuk belajar menggunakan media konvensional seperti merangkum ulang, menggambar ulang, belajar dengan alat peraga, membaca berulang-ulang, berdiskusi dengan sesama mahasiswa kedokteran, dan membuat jembatan keledai.

Dari hasil pembuatan hingga pengujian pengguna, aplikasi ini memiliki kelebihan pada konten yang lebih interaktif dan memudahkan belajar dengan praktis. Sebagai media pendukung pembelajaran anatomi dan fisiologi untuk mahasiswa kedokteran, gaya bahasa dalam materi dalam aplikasi harus memuat nama-nama struktur dalam bahasa latin dan detail. Penggunaan animasi dalam setiap materinya, juga sangat membantu dalam mempelajari proses-proses yang terjadi pada kejadian fisiologis dalam sistem kardiovaskular.

\section{B. Saran}

Di dalam aplikasi kedokteran ini masih terdapat kekurangan yang belum memenuhi kebutuhan belajar mahasiswa kedokteran. Beberapa kekurangan tersebut adalah desain antarmuka aplikasi yang belum fleksibel dengan beberapa jenis resolusi ponsel, beberapa fungsi fitur yang belum bekerja dengan baik, dan konten materi yang belum sepenuhnya dimasukkan dan divalidasi oleh pakar kedokteran.

Untuk meningkatkan pengalaman pengguna dalam belajar anatomi dan fisiologi, masih perlu adanya tambahan integrasi media yang mewadahi kebutuhan pengguna dalam belajar berbentuk media fisik. Media tersebut dapat berupa jurnal visual yang berisi aktivitas mewarnai, teka-teki silang, atau permainan sederhana lainnya sebagai cara belajar yang lebih kreatif. Sehingga, integrasi media aplikasi dan jurnal visual tersebut dapat meningkatkan kekuatan konsep desain "Personal Journal for Future Doctors".

\section{DAFTAR PUSTAKA}

[1] Konsil Kedokteran Indonesia, "Standar kompetensi dokter indonesia," Jakarta, 2012.

[2] F. Martini, J. Nath, and E. Bartholomew, Fundamental of anatomy \& physiology, 9th ed. Benjamin-Cummings Publishing Company, 2011. 